Madrygal. Revista de Estudios Gallegos

ISSN: 1138-9664

\title{
Fuentes para la Historia de la "quinta provincia": el Archivo de la Federación de Asociaciones Gallegas de la República Argentina
}

Ruy Farías ${ }^{1}$

Recibido: 19 de febreiro de 2016 / Aceptado: 12 de agosto de 2016

Resumen. En el balance de los siglos XIX y XX, la República Argentina ha sido el más importante destino mundial de las migraciones originadas en Galicia. Su capital, Buenos Aires, fue además durante por lo menos cinco décadas de la pasada centuria la ciudad con la mayor cantidad de gallegos del planeta. En ella gestaron un vasto tejido institucional del cual, a partir de 1921, formó parte la Federación de Asociaciones Gallegas de la República Argentina. Con el paso del tiempo dicha entidad generó una enorme y valiosa masa de documentación que, junto a la de varias sociedades microterritoriales gallegas y la del extinto Centro Republicano Español de Buenos Aires, conforman un impresionante acervo documental. En el presente escrito se analizan la composición y características de los fondos del archivo de la Federación, al mismo tiempo que se ofrece una interpretación del valor de los mismos y las posibilidades que ofrecen a la investigación de las migraciones y el exilio gallego en la Argentina.

Palabras clave: Migraciones; exilio republicano español; Galicia; Buenos Aires; asociacionismo gallego; fuentes de información.

\section{[gl] Fontes para a Historia da "quinta provincia": o Arquivo da Federación de Aso- ciacións Galegas da República Arxentina}

Resumo. No balance dos séculos XIX e XX, a República Arxentina foi o máis importante destino mundial das migracións orixinadas en Galicia. A súa capital, Bos Aires, foi ademais durante polo menos cinco décadas da pasada centuria a cidade coa maior cantidade de galegos do planeta. Nela xestaron un vasto tecido institucional do cal, dende 1921, formou parte a Federación de Asociaciacións Galegas da República Arxentina. Co paso do tempo a devandita entidade xerou unha enorme e valiosa masa de documentación que, xunto á de varias sociedades microterritoriais galegas e a do extinto Centro Republicano Español de Buenos Aires, conforman un impresionante acervo documental. No presente escrito analízanse a composición e características dos fondos do arquivo da Federación, ao mesmo tempo que se ofrece unha interpretación do valor dos mesmos e as posibilidades que ofrecen á investigación das migracións e o exilio galego na Arxentina.

Palabras chave: Migracións; exilio republicano español; Galicia; Bos Aires; asociacionismo galego: fontes de información.

\section{[en] Sources for the History of the "Fifth Province": the Archive of the Federation of Galician Associations of the Argentine Republic}

\begin{abstract}
During XIX and XX Centuries Argentina was the most important destination for the migrations originated in Galicia. For at least five decades of the past century its capital city -Buenos Aires- was the city with the larger number of Galicians in the world. They created an extensive web of institutions of which since 1921 the Federation of Galician Associations of the Argentine Republic was part of. Over time, this institution has generated a significant volume of documentation that together with the archives of several micro-territorial Galician organizations and the extinct Republican Spanish Center of Buenos Aires make up for an impressive documental collection. In this paper I analyze the composition and characteristics of the Federations' archive and I assess its value and the potential it has for the research of the Galician migration and exile in Argentina.
\end{abstract}

Keywords: Migrations; Spanish Republican Exile; Galicia; Buenos Aires; Galician Associationism; Sources.

Consejo Nacional de Investigaciones Científicas y Técnicas; Universidad Nacional de San Martín, Cátedra Galicia-América; Museo de la Emigración Gallega en la Argentina.

E-mail: ruyfarias@conicet.gov.ar 
Sumario. 1. Introducción 2. La presencia gallega en la Argentina y su asociacionismo en Buenos Aires. 3. Los fondos documentales de la Federación de Asociaciones Gallegas de la República Argentina. 4. A modo de cierre. 5. Referencias bibliográficas.

Como citar: Farías, R. (2017): "Fuentes para la Historia de la "quinta provincia": el Archivo de la Federación de Asociaciones Gallegas de la República Argentina", Madrygal. Revista de Estudios Gallegos 20 (Núm. especial), pp. 87-99.

\section{Introducción}

Como afirmara hace algunos años Xosé Manoel Núñez Seixas (2009) en un texto que lleva el sugestivo título de "¿Para qué sirve conservar el patrimonio de la emigración?", la colectividad gallega de Buenos Aires es uno de los principales lugares de memoria de lo que fue (y todavía es) la emigración galaica, pudiendo encontrarse en muchas de sus instituciones verdaderos tesoros de esa memoria. Atentos a la opinión de dicho historiador - uno de los mayores especialistas sobre las migraciones y exilios galaicos-, nos avocaremos al análisis de la composición, el valor y las posibilidades que ofrecen a las ciencias sociales los fondos documentales de la Federación de Asociaciones Gallegas de la República Argentina (FAGA), actualmente en proceso de salvaguarda, catalogación y digitalización por el Museo de la Emigración Gallega en la Argentina (MEGA), entidad específicamente creada para la recuperación, conservación y difusión del patrimonio material e inmaterial de la emigración y el exilio gallego en el país ${ }^{2}$.

\section{La presencia gallega en la Argentina y su asociacionismo en Buenos Aires}

Históricamente, la Argentina ha sido el más importante de los destinos de la emigración gallega a nivel mundial. Los flujos procedentes de
Galicia fueron igualmente significativos para el país austral y para la reconfiguración social que experimentó entre finales del siglo XIX y comienzos del XX. Algo más de 1000000 de gallegos ingresaron a él entre 1857 y 1930 (el 17\% de toda la inmigración europea, y su mayor grupo étnico-regional), la mayoría de ellos en el corto lapso que va de 1904 a 1913. Tiempo después, superada la coyuntura negativa signada por el encadenamiento de la crisis económica de 1929, la Guerra Civil Española y la Segunda Guerra Mundial, una última "oleada migratoria" (1946-1962 llevaría a la Argentina otros 110000 gallegos más. Aunque a lo largo de esos 100 años casi la mitad regresó a su tierra de origen, los 600000 definitivamente radicados en el territorio argentino, junto a su tendencia a concentrarse en las zonas urbanas del Litoral pampeano y particularmente en Buenos Aires, generó fenómenos tales como que la ciudad porteña fuese desde la segunda década del siglo XX y durante buena parte de dicha centuria, la más importante urbe galaica del planeta. No obstante, la impronta de Galicia en la orilla occidental del Río de la Plata excede largamente el impacto de su notable volumen demográfico ${ }^{3}$.

Desde mediados de la década de 1980, se publicaron un gran número de estudios de caso (y también algunas obras de síntesis) que hicieron posible la comprensión de los factores macroestructurales y microsociales del fenómeno, el conocimiento de la inserción espacial y laboral del grupo en su principal destino austral (Buenos Aires y su periferia), su obra socioeducativa en la urbe porteña, la dinámica política y cultural de su asociacionismo, la aparición y desarrollo de identidades alternativas $u$ opuestas a la española, las características de sus dirigencias y liderazgos, las imágenes, estereotipos, prejuicios y

2 Sobre la Federación y el Museo, véase Díaz 2007 y Chiloteguy 2015. El presente escrito no aborda la descripción y análisis de las fuentes personales (epistolarios, documentación personal, fotografías, testimonios orales, etc.) reunidas por el MEGA a partir de su creación, un acervo igualmente necesario para la reconstrucción de la presencia gallega en el país.

3 Sobre la inmigración europea en la Argentina, la gallega a América y su corriente específicamente argentina, véase Devoto 2003, Villares y Fernández 1996 y Núñez Seixas 2007.

4 Un análisis de la bibliografía sobre el tema, en Núñez Seixas 2010. Sin pretensión de exhaustividad, resultan de obligada consulta las obras de o contenidas en Núñez Seixas 1992, 1998, 2000, 2001, 2002, 2006; Sánchez Alonso 1992, Cagiao Vila 1997, 1999; Duarte 1998, Fernández y Moya 1999, Moya 2004, Da Orden 2005, 2010; Núñez Seixas y Soutelo Vázquez 2005, Bernasconi y Frid 2006, Lojo, Guidotti de Sánchez y Farías 2008, De Cristóforis y Fernández 2008, De Cristóforis 2009, 2010, 2011; Farías 2010, Cerdeira Louro 2010, Farías Iglesias 2010, García Sebastiani 2011, Merino Hernando 2012 y Vázquez González 2015. 
formas latentes o concretasde xenofobia, el rol de la mujer, etc. ${ }^{4}$. A fin de contextualizar mejor el tema a desarrollar, repasaremos algunas conclusiones de esa vasta producción.

Después de encontrar donde vivir y un modo de ganarse la vida, el siguiente paso en la adaptación de los migrantes acostumbraba ser la recreación de una "red social secundaria". Como parte de esa dinámica, los procedentes de Galicia fundaron o se afiliaron a una plétora de asociaciones voluntarias de corte étnico, ya sea genéricamente españolas o específicamente galaicas, por lo que buena parte de su integración tuvo lugar a través de su participación en una colectividad o comunidad emigrante, un espacio de interacción social en el que recreaban el aquél de procedencia. Las entidades nacionales españolas precedieron cronológicamente a las regionales gallegas, y a partir de la fundación de la Sala Española de Comercio (1852) se desarrolló un abundante tejido institucional panhispánico formado por asociaciones mutualistas, patrióticas, recreativas, etc. Hacia 1914 existían unas 250 entidades de ayuda mutua con unos 110000 socios en total, lo que implica que 13 de cada 100 españoles en el país se hallaban mutualizados (Devoto y Fernández 1990). No obstante, puesto que los gallegos fueron entre 1860 y 1960 al menos la mitad de todos los peninsulares en la Argentina, tras el nombre de "española" de una sociedad cualquiera solía ocultarse una mayoría gallega entre sus dirigentes y afiliados.

Pero, además, desde el último cuarto del siglo XIX afloró también un rosario de instituciones propiamente galaicas, las cuales desarrollaron prácticamente todas las posibilidades del asociacionismo étnico, combinando la procedencia geográfica (regional, provincial, comarcal, municipal o parroquial) con los objetivos específicos que cada institución perseguía (mutualistas médicas, beneficencia, culturales, políticos, recreativos, deportivos, etc.), que -por lo demás- solían ser múltiples. Sin entrar en análisis pormenorizados, resulta evidente que el migrante gallego -mayoritariamente procedente del mundo rural o marinero- experimentaba al desembarcar en la metrópoli porteña un importante choque cultural, contraste que lo empujaba a practicar la solidaridad étnica con sus coterráneos a fin de amortiguar el impacto y acomodarse mejor a las nuevas condiciones. Pero la experiencia de la emigración contribuyó también a cambiar la mentalidad de muchos, en un proceso de dimensiones tanto individual como colectivo. Quien se sumergía en esa aventura no sólo descubría en la Argentina un mundo donde la movilidad social ascendente era una opción real: también se le revelaba otro de nuevas relaciones sociales, encuadrado en experiencias de confrontación de clase y de oficio. Esa toma de conciencia influyó en que también valorase las ventajas de la asociación y, sumado al importante papel de las élites étnicas, explica la creación de un amplio tejido de instituciones gallegas de ámbito regional, comarcal y local.

Aunque el asociacionismo galaico tuvo precedentes en el período tardocolonial, su eclosión coincidió con el comienzo de la emigración transoceánica masiva, en las últimas dos décadas del siglo XIX. Tras la desaparición en 1892 del primer centro gallego en Buenos Aires (de 1879), la capital argentina no conoció hasta 1907 ninguna gran sociedad mutualista de ámbito galaico. Fue entonces cuando, coincidiendo con el arribo de las grandes oleadas de migrantes galaicos, nació el nuevo Centro Gallego de Buenos Aires, que para la década de 1930 se convertiría en la entidad mutual más grande de la Argentina y de la América hispana ${ }^{5}$. A lo largo de las décadas siguientes surgieron también varias sociedades regionales (asilos, centros culturales, políticos y otros por el estilo), cuatro centros provinciales (uno para cada provincia) y un sinfín de asociaciones microterritoriales. Dicho término, acuñado por Vicente Peña Saavedra (1991), alude a formas asociativas polivalentes que adoptaban como marco espacial de actuación entidades geográfico-administrativas propias del país de origen inferiores a la provincia como la parroquia, el municipio o la comarca (a veces también el partido judicial o distrito), ámbitos territoriales de relación e interacción que constituían verdaderas esferas de recreación del espacio social.

El puñado de socios iniciales creció a 11796 en 1923, y en 1932 eran ya 39 118. En 1961 la institución alcanzaría su máximo histórico: 104855 (Cagiao Vila y Peña Saavedra 2008). Aunque antigua y limitada a sus primeras tres décadas, la mejor Historia del Centro continúa siendo la de Rodríguez Díaz (2000). 
A partir de la fundación de la primera de estas instituciones en 1904, surgió tal cantidad de ellas que acabaron por constituir un fenómeno que, por su volumen y características, particularizan a la colectividad galaica dentro del asociacionismo hispánico rioplatense ${ }^{6}$. Las solidaridades locales pervivieron en la otra orilla del océano, y fueron en un comienzo de carácter más inmediato y vinculante que la gallega o española, siendo indudable el papel jugado por esas instituciones como ámbitos de socialización de los migrantes, y muchas veces también de sus hijos y nietos. En el caso de las mujeres, cuya dedicación laboral se desarrolló con mayor frecuencia en el ámbito doméstico, alcanzaron aún mayor relevancia, pues el acceso a las sociedades como lugares de contacto externo representó para muchas la única posibilidad de facilitar las relaciones personales, lo que incidirá en el comportamiento endogámico del que hicieron gala ${ }^{7}$.

La pervivencia de las solidaridades locales, y el alto promedio de retornos que -al menos hasta la guerra civil- se verificó junto al por lo general corto período de estancia de los migrantes allende el mar, favorecieron el mantenimiento de los vínculos con las comunidades parroquiales o municipales de origen. $\mathrm{Y}$ estos lazos se canalizaron y cristalizaron, principalmente, a través de la orientación de sus instituciones étnicas, que desde sus comienzos incluyeron entre sus objetivos, además del socorro mutuo para sus miembros, la coordinación de esfuerzos para llevar a cabo iniciativas diversas en el país de origen. Su evolución y naturaleza sociopolíticas presentan características muy diversas, pero la mayoría exhibía un ideario político-social moderado vinculado a un proyecto democrático-progresista de contornos difusos, inicialmente centrado en problemáticas relacionadas con el poder local, que puede definirse como anticaciquil, de construcción de la sociedad civil y de regeneración ${ }^{8}$. A menudo fueron llamadas sociedades de instrucción, mas, en puridad esa denominación sólo correspondería a las que tuvieron como objeto la creación o dotación de establecimientos escolares en sus lugares de origen (unos 326 , repartidos por varias zonas de Galicia), sin duda uno de los fines más importantes de estas entidades. La finalidad implícita en dicha obra era contribuir a la regeneración individual del campesino, hacerlo consciente de sus derechos, prepararlo para luchar por su emancipación, capacitarlo para la acción colectiva $\mathrm{y}$, según lo entendían sus propulsores, terminar así con el caciquismo y fanatismo religioso que invalidaba sus derechos democráticos.

Aunque, como queda dicho, los fines mutualistas también jugaron inicialmente un papel relevante, fueron perdiendo importancia a medida que las grandes instituciones benéficoasistenciales (y en particular el Centro Gallego de Buenos Aires) se asentaron y desarrollaron. De tal modo, con el tiempo la mayoría acabó concentrándose en las actividades lúdico-recreativas. Y aunque muchas conservaron una larga vida (llegando algunas hasta nuestros días), desde la victoria franquista en Galicia sus posibilidades de actuación a favor de sus comunidades de origen se circunscribieron-con contadas excepciones-prácticamente al campo de la beneficencia.

Por otra parte, su intervención en la dinámica social y política su tierra de origen no se limitó a una serie de inconexos arrestos individuales, sino que desde temprano surgieron iniciativas de ámbito "regional", superadoras del localismo de la actuación de cada una, que se plasmaron fundamentalmente en acciones de apoyo al movimiento agrarista galaico. Esos proyectos federativos se sucedieron a lo largo de la segunda y tercera década del siglo pasado, y en 1921 nació, como producto de la coalición de varias sociedades con clara vocación de intervención sociopolítica en Galicia, la Federación de Sociedades Gallegas, Agrarias y Culturales (FSG), que llegaría a agrupar más de medio centenar de entidades a mediados de la década de 1950, con unos 15000

6 En Buenos Aires habrían existido entre 1904 y 1936 no menos de 327 (474 para todo el país de 1901 a 1933 ). No obstante, a partir de 1930, como consecuencia de la caída de los flujos migratorios, se advierte la desaparición de algunas y la unificación de otras de un mismo ámbito territorial, fenómeno que se aceleró durante y después de la guerra de 1936. Con todo, aunque a un ritmo mucho menor, la creación (o recreación) de estas asociaciones continuó en las décadas siguientes.

Sobre la conducta matrimonial de las migrantes gallegas, véase Farías Iglesias 2010: 315-364.

8 En relación con la dinámica sociopolítica de Galicia en el primer tercio del siglo XX, véase Villares 2004. 
afiliados. Influenciada sucesiva o simultáneamente por el agrarismo, el socialismo, el nacionalismo gallego y el comunismo, se caracterizó hasta hoy por su compromiso con la realidad de Galicia y por su vocación de intervención en la modernización de su sociedad y vida política. Dicha disposición se encauzó inicialmente en el apoyo prestado al movimiento anticaciquil y antiforal del campesinado gallego. Más tarde, y pese a sufrir una escisión en 1929, fue capaz de actuar de manera sensible en la política galaica de la Segunda República Española, enviando delegados que participaron en las elecciones apoyando candidaturas republicanas y galleguistas (algunos de los cuales alcanzaron el rango de diputados en el parlamento español), apoyando las reivindicaciones del país ante el Estado central, la campaña a favor de su Estatuto de Autonomía y, tras el golpe de Estado del 18 de julio de 1936, al legítimo gobierno de España. Si bien fueron muchas las instituciones hispanas de la Argentina comprometidas con la causa republicana durante dicha coyuntura (Montenegro 2002), la Federación destacó por su frenética actividad que, lejos de finalizar con la derrota de 1939, continuó trabajando en favor de los exiliados y refugiados, y con los que en la península sufrieron la represión del régimen de Francisco Franco. Hasta la llegada de la "transición española", la FSG fue el albergue de varios de los elementos más combativos del galleguismo y el republicanismo emigrante y exiliado, encarnando la memoria republicana, la oposición a la dictadura franquista y la lucha por la restauración democrática en España.

\section{Los fondos documentales de la Federa- ción de Asociaciones Gallegas de la Repúbli- ca Argentina}

Hasta hoy, la mayoría de las investigaciones sobre los gallegos en la Argentina se focalizaron en la capital del país y en la etapa de inmigración "masiva" (aprox. 1880-1930), de modo que poco o nada informan sobre otros puntos del territorio, o sobre la "última oleada" migratoria ${ }^{9}$. Sin embargo, dado que la Federación se constituyó en 1921, y que tanto ella como las microsociedades que coaligó vivieron su período álgido entre la tercera y la octava década del pasado siglo, la documentación de su archivo hace factible introducir algunas correcciones en dicha tendencia. Con el transcurso de los años la FSG (a partir de 1991, oficialmente Federación de Asociaciones Gallegas de la República Argentina) generó una enorme y valiosa masa documental, a la que se unen la de varias docenas de sociedades federadas (algunas preexistentes a la misma Federación, como ocurre en los casos de la Sociedad Hijos de las Tres Parroquias de Dodro, o La Antorcha. Sociedad Pro Cultura de los Residentes de Cristiñade en Buenos Aires), y también una parte sustancial de la del extinto Centro Republicano Español de Buenos Aires (CRE). Ello totaliza más de 960 unidades de conservación formadas por registros de socios, libros de actas de asambleas, de comisiones directivas, de fiestas y de "damas y señoritas", documentación contable, correspondencia enviada y recibida, fotografías, folletería y programas de actividades lúdicas, etc. Decenas de miles de documentos elaborados de 1910 a nuestros días, fuentes cualitativas en muchos casos de tipo nominativo (pues contienen datos filiatorios de diferentes individuos), por lo que pueden ser utilizadas también de forma agregada (cuantitativa). Esta masa documental se encuentra en proceso de sistemática clasificación, puesta en valor y digitalización por parte del MEGA, institución que, desde su creación en 2005, ha ejecutado sucesivos proyectos de conservación en el marco de su Programa de Colecciones, con la finalidad de salvaguardar aquella y avanzar también con los programas de Documentación, Exposición e Investigación (Chiloteguy 2015).

Esos documentos tienen, ante todo, un valor inmaterial superlativo, pues se hallan "atados a las vivencias de una comunidad, a su posición dentro de una sociedad de inmigrantes, a su autoestima y orgullo", lo que les da un valor "no en sí, sino en función del significado

9 Los que sobrepasaron la línea 1930/1939 (Schwarzstein 2001, Devoto 2001, Fernández Vicente 2005, Ortuño Martínez 2010, Fasano 2014, etc.), generalmente se avocaron al estudio del exilio republicano (gallego o genéricamente español), los condicionantes y efectos de las políticas migratorias del franquismo, y la relación de éstas con las ideas, metas e iniciativas del gobierno argentino. Como excepción a esa regla, véanse los trabajos reunidos en Farías 2010. 
otorgado por un colectivo" (Núñez Seixas 2009: 1). Testimonian como, a consecuencia de lo que la Sociedad Fomento de Porriño y su Distrito caracterizaba en 1916 un afán de "mejoramiento y engrandecimiento moral, material y político" (Núñez Seixas 2000: 378), hubo un tiempo en el que los emigrantes ayudaron (a través de sus remesas "materiales" e "inmateriales") a la regeneración de Galicia y a su modernización ${ }^{10}$.

Otra parte de los fondos permite ahondar en cómo los migrantes gallegos se movilizaron en apoyo de la legalidad republicana durante la guerra de 1936-1939. La Federación dio vida a un organismo específico para coordinar la ayuda generada por la intensa movilización de la comunidad galaica (la Agrupación Gallega de Ayuda al Frente Popular, luego denominada Central Gallega de Ayuda el Frente Popular Español, Central Gallega de Ayuda a los Refugiados Españoles y, finalmente, Sección Solidaridad de la FSG), de los que se conservan sus libros de actas y otros documentos elaborados entre 1937 y 1949. Del mismo modo, existen otros fondos y sub-fondos correspondientes tanto a la Coordinación de Organismos Republicanos Españoles, como a algunos de los comités que muchas de las sociedades federadas crearon con fines similares (Castroverde de Ayuda al Frente Popular Español, Pro Ayuda a España de la Sociedad Hijos del Ayuntamiento de Carnota, Ayuda a la República Española del P. J. de Quiroga, Comité de Castroverde, Baleira y Fonsagrada de Ayuda al Frente Popular Español, etc.). Y también documentos en los que puede verse como hubo quienes, haciendo gala de un grado de compromiso que en ocasiones les costó la vida, optaron por regresar a la Península y participar de lleno en el conflicto $^{11}$. Del mismo modo, el rico epistolario de la FSG y su órgano de prensa (Galicia, por entonces de periodicidad semanal) constituyen para este tema otras tantas fuentes ineludibles.
Los fondos del CRE son otra vía de entrada al tema del conflicto bélico 1936, su relación con la emigración gallega y el exilio republicano en la Argentina y, más en general, para el estudio del republicanismo español en el país. Nacido en 1904, durante varias décadas el Centro llevó a cabo una importante actividad político-cultural a través de su Comisión de Cultura, su periódico (España Republicana), sello editorial (Patronato Hispano Argentino de Cultura), sosteniendo una biblioteca $y$ hemeroteca, y emitiendo durante los decenios de 1950 y 1960 un programa radial. Cuando se extinguió, a finales de la década de 1980, su documentación fue donada a la FAGA, incluyendo más de 6.000 solicitudes de ingreso labradas entre 1914 y 1985, correspondientes tanto al CRE como a las agrupaciones Navarra Republicana y La Tierrina Leal (asturiana). Los datos que en ella se consignaron (nombres y apellidos de los socios, fecha y lugar de nacimiento, dirección en la Argentina, filiación política, etc.), hacen posible la reconstrucción del perfil socioprofesional y político de esas personas. Además, entre la masa de documentación recibida figuraba también una parte de la generada por la Cámara de Comercio Republicana Española, entidad creada por Manuel Puente (mecenas de Alfonso D. Rodríguez Castelao y de varios emprendimientos culturales de la colectividad galaica) que actuó entre 1938 y 1945.

Aunque la mayor parte del resto de los fondos del archivo de la FAGA, refieren a cuestiones menos impactantes para quienes se interesan básica o exclusivamente por los grandes personajes políticos e intelectuales, o las prosopografías heroicas, resultan sumamente útiles para abordar algunos de ítems fundamentales del proceso de integración del colectivo migrante. Piénsese, por ejemplo, en el largo debate historiográfico de los estudios sobre las migraciones en la Argentina, relacionado

10 Véase, por ejemplo, el manifiesto con el que principia el Libro de Actas del Comité Auxiliar de las Sociedades Agrícolas de Puenteareas en Buenos Aires (Archivo FAGA-MEGA, Fondo Centro Renovación de Puenteareas, Subfondo Comité Auxiliar de las Sociedades Agrícolas de Puenteareas en Buenos Aires, Libro de Actas, 22-II1910, p. 2).

11 Véase, por ejemplo, la carta de Ramón T. Fernández al Centro Renovación de Puenteareas, donde se relata la suerte del socio del mismo, Amador Iglesias, muerto en 1938 durante los bombardeos de la aviación franquista a Barcelona, pocos días después de arribar a la misma desde la Argentina (Archivo FAGA-MEGA, Fondo Centro Renovación de Puenteareas, Correspondencia enviada y recibida). Sobre la participación en el Ejército republicano de voluntarios llegados desde la Argentina, véase González et al. 2008. 
con la pregunta de si el país se constituyó en una sociedad acrisolada o en una plural (Devoto y Otero 2003), y la utilización en él de tres indicadores cuantificables y comparables que Milton M. Gordon (1964) relaciona con la "asimilación estructural informal": pautas matrimoniales, residenciales y participación en asociaciones voluntarias. Aunque a pequeña escala, el archivo de la Federación ofrece materiales para su análisis, y para el de aspectos tales como la composición del stock gallego en el país o su inserción socioprofesional en él ${ }^{12}$.

Los registros de socios de las instituciones étnicas constituyen una herramienta útil para enmendar, aunque sea a través de pequeños estudios de caso, ciertas lagunas de las fuentes oficiales argentinas $^{13}$. El archivo de la FAGA conserva más de 40 correspondientes a un mínimo de 16 entidades, y también otras tantas series de solicitudes de ingreso, como las de la Sociedad del Ayuntamiento de Castro Verde y sus Contornos (labradas entre 1927 y 1957), la Sociedad de Residentes del Municipio de Porriño (confeccionadas entre 1938 y 1965), etc. En casi todos los casos, esos documentos consignan el nombre y apellido del nuevo socio (y de quien lo presentó), su edad, nacionalidad, provincia, ayuntamiento y pueblo (sic) de nacimiento, su profesión y domicilio en la Argentina. La posibilidad de realizar comparaciones entre las distintas series permite, por ejemplo, ilustrar los variados patrones residenciales desarrollados por los distintos grupos comarcales, municipales y parroquiales. En algunas ocasiones, además, la existencia de más de un recuento en un mismo registro hace posible observar -someramente- la movilidad espacial del grupo.
El indicador de la inserción socioprofesional de los migrantes (y más aún el de su movilidad social, que no debe asimilarse a la laboral) adolece de graves dificultades en relación con las fuentes disponibles para su tratamiento, sea desde un enfoque macro basado en datos censales éditos, sea desde aquellos que realizan un seguimiento temporal de los individuos a través de las planillas originales de los censos, donde el dato "ocupación" presenta serios límites de cobertura y confiabilidad, debido a la existencia de ocupaciones sumamente generales o sin un status definido, y al casi total silencio sobre las ocupaciones femeninas. A mayores, quien pretenda analizarlo en relación a un grupo étnico-regional determinado debe enfrentar dos problemas más: éstas fuentes no discriminan la región de origen, resultando imposible deslindar a quienes nacieron en Galicia del resto de los españoles; las últimas cédulas censales disponibles son de 1895, período anterior incluso al momento álgido de la inmigración gallega en el país. Los registros de socios y solicitudes de ingreso pueden proporcionar algún paliativo en combinación con otros documentos como las actas de los registros civiles que contienen datos de ocupación, o con los registros de personal de una o varias fábricas. A grandes rasgos, el análisis de la composición social de los miembros de las asociaciones microterritoriales gallegas revela que las mismas se hallaban por lo general integradas por empleados y dependientes de comercio, seguidos por comerciantes y obreros manuales con y sin cualificación. Es el caso de las solicitudes de varones gallegos que entre 1944 y 1958 se inscribieron en Agrupación Cultural y Recreativa Residentes de Galicia

12 Empero, a la hora de calibrar el grado de representatividad de quienes se asociaban a estas instituciones respecto a la totalidad de la comunidad gallega, conviene no perder de vista que, sólo en sus ejemplos más felices, las entidades que reproducían como marco de referencia ámbitos de relación e interacción social de origen de los inmigrantes inferiores a la provincia, alcanzaron a reunir un 33-50\% de sus connaturales emigrados en Buenos Aires. De hecho, la mayoría de las veces sus porcentajes podían ser muy inferiores. Por otra parte, como recordaba hace tiempo Samuel Baily (1996), su masa societaria no solía estar integrada por inmigrantes "típicos", sino que en ellas se encontraban sobrerrepresentados los segmentos más "estables" y económicamente prósperos de la comunidad inmigrante, por lo que deben evitarse los pasajes indiscriminados de lo observado en la colectividad a la totalidad de la colonia. Con todo, en lo que respecta a las migraciones galaicas a la Argentina post-1946, la dramática disminución de la tasa de retorno en relación con los patrones anteriores a 1930, reduce sensiblemente el riesgo de subrepresentar a los emigrantes más "móviles" (aquellos que sí regresaron a su tierra de origen).

13 Por lo general, aquellas que abarcan la totalidad de la población del país (como las "cédulas censales" de los recuentos nacionales de población) tienden a ser escasas en detalles particularizantes, mientras que otras más generosas en cuanto al tipo de información que brindan (como la provincia o comuna de nacimiento), resultan habitualmente más restringidas en cuanto al universo de emigrantes alcanzados. Reflexiones sobre las fuentes, sus posibilidades y límites, en Bernasconi 1995, VV.AA. 1996. 
en Lanús, que nos muestran la existencia de un porcentaje de "empleados", comerciantes y "trabajadores artesanos" muy superior a la media de la colonia gallega en ese municipio de la periferia porteña, una presencia relativamente escasa de trabajadores urbanos con y sin cualificación, y la práctica inexistencia de marineros, ocupaciones todas que resultan claramente perceptibles al analizar otras fuentes de mayor alcance demográfico, como el Registro General de Matrícula del Consulado General de España en Buenos Aires (1939-1960) ${ }^{14}$. Con todo, esas generalizaciones no deben anular el análisis pormenorizado de las series disponibles, las que podrían revelar la existencia de matices entre las diferentes entidades.

En ocasiones, la documentación de las microsociedades también facilita la aproximación a la composición del stock gallego en diferentes puntos del país. Por caso, las solicitudes de ingreso de la institución antedicha permiten, debido a su pretensión de nuclear a todos los gallegos residentes en el municipio homónimo, una primera mirada a la composición provincial del colectivo galaico ${ }^{15}$. Otras veces, incluso, hacen posible visualizar el peso relativo que las diferentes parroquias o ayuntamientos pudieron tener en la conformación de las entidades de ámbito municipal o comarcal.

El carácter nominativo de estas fuentes posibilitan, además, la reconstrucción de familias, círculos de sociabilidad y, en definitiva, del vasto universo social de estas personas. Gracias a ello, constituyen -potencialmente- una prueba de la existencia de redes microsociales de vecindad y parentela operantes en el lugar de destino, proximidad residencial y/o de lugar de trabajo, y también de como los liderazgos étnicos conllevan una combinación de intereses entre notables y activistas políticos. A mayores, al identificar tanto el lugar de nacimiento del sujeto como su domicilio en la Argentina, dejan abierta la posibilidad de ampliar la base documental mediante la incorporación de información obtenida de fuentes elaboradas en ambos sitios, metodología empleada por
José C. Moya (2004) en su modélico trabajo sobre los españoles en Buenos Aires entre 1850-1930.

Desde luego, el estudio de las formas de sociabilidad constituye otro ítem importante dentro del campo de los estudios migratorios. No existen dudas sobre el destacado papel que las frecuentes fiestas, almuerzos, pic-nics (reuniones campestres), etc., de las sociedades gallegas jugaron en la pervivencia de las solidaridades locales: al intentar reproducir o mantener pautas y costumbres de la sociedad de origen, constituyeron los mecanismos más evidentes (aunque no únicos) de expresión de la identidad. Sin embargo, en dichos eventos se combinaban elementos tradicionales (gaiteros, alimentos del país, etc.) con otros propios de la sociedad de acogida (música criolla o también foránea pero de moda, asados, etc.), generando un ámbito tanto para la recreación de los ambientes culinarios típicos y la música propia como para su hibridación. De tal modo, en este tipo de convivencias se refleja cierta armoniosa mixtura con los nuevos hábitos adquiridos, y tanto en la comida como en la música se produce una especie de sincretismo entre las costumbres de los migrantes y las de la sociedad receptora ${ }^{16}$. Las omnipresentes comisiones de fiestas (habitualmente integradas por socios femeninos) y sus documentos (libros de actas, programas de actividades recreativas, carteles y folletos en general), son otras tantas ventanas a una dinámica clave para la sociabilidad del grupo, dada su alta "rentabilidad" en términos comunitarios y asociativos. Por otra parte, tales acontecimientos, junto a las también numerosas comisiones "de damas y señoritas", constituyen prácticamente la única ventana desde donde atisbar la por lo general "invisible" participación femenina en la vida de la colectividad. Aunque hasta no hace mucho tiempo la mayoría de las instituciones galaicas relegaron la presencia femenina a una situación de subordinación respecto del hombre, siendo muy infrecuente hallar mujeres en las comisiones directivas, ellas resultaban en

14 Cf. Archivo FAGA-MEGA, Fondo Residentes de Galicia en Lanús, Solicitudes de ingresos de socios, 1-810; Farías Iglesias 2010: 604-625.

15 Véase Archivo FAGA-MEGA, Fondo Residentes de Galicia en Lanús, ya citado.

16 Sobre la fiesta gallega entre fines del siglo XIX y comienzos del XX, y su relación con la identidad del grupo, véase Núñez Seixas 2002. Para la alimentación, apuntes en Cagiao Vila 1999 y Farías 2011. 
cambio sumamente importante en su rol de organizadora de actos sociales y veladas festivas. Asimismo, las noticias difundidas por los órganos de prensa societarios anunciando enlaces matrimoniales, nacimientos, efemérides, defunciones, viajes y cambios de residencia, son también vías de ingreso a la sociabilidad étnica de los migrantes y, más específicamente, a la presencia femenina en ella.

El indicador del asociacionismo étnico también permite sumergirse en las estrategias desplegadas por las élites para la construcción de consensos, y de la conciencia social del grupo. El estudio de las dirigencias, los notables y los liderazgos dentro de las distintas colectividades migrantes, implica llamar la atención sobre el hecho de que las mismas no son un producto "espontáneo" de la experiencia social, ni -a menudo- una identidad preexiste al momento de emigrar a un nuevo país ${ }^{17}$. Por el contrario, es en éste donde, interactuando con paisanos e instituciones comunitarias, se descubren como colectivo diferenciado. Un papel importante en dicho proceso corresponde a los discursos nacional-patrióticos articulados y diseminados por los grupos dirigentes. Las elites sociales, políticas o intelectuales de un colectivo o grupo étnico juegan un papel fundamental en la definición, fijación y difusión de aquellas imágenes o estereotipos que definen tanto al propio grupo como a los demás colectivos con los que éste entra en interacción; contribuyen de manera decisiva a la conformación y codificación de los imaginarios colectivos del endogrupo, mediante una modificación y canonización selectiva de sus trazos idiomáticos, de tradiciones preexistentes, de códigos de conducta compartidos y demás materiales etnoculturales en sentido amplio, en un verdadero proceso de imaginación de la comunidad ${ }^{18}$. Más allá de su aparente esterilidad, las actas de asamblea y de comisión directiva facilitan la aproximación a los discursos de las elites y, desde allí, a la cuestión de la construcción de la identidad del grupo y la relación de la dirigencia étnica con la masa de inmigrantes anónimos. Consecuentemente, en tanto vehículo de expresión del pensamiento de los líderes del colectivo, resulta también fundamental el análisis de la prensa étnica. A partir de 1922, la FSG contó con órganos propios: El Despertar Gallego, que desde 1930 pasó a llamarse Galicia, y también Acción Gallega, editado por la FSG disidente durante buena parte de la década de 1930. Las mismas se encuentran resguardadas en la hemeroteca de la FAGA, también rica en otras cabeceras de la emigración y el exilio español y gallego en la Argentina. Por otra parte, el análisis de las estrategias de la dirigencia comunitaria, junto al de los diferentes círculos concéntricos de identificación local, cuestiones político-ideológicas y los mismos avatares de los flujos migratorios, permitirá entender las ampliaciones, escisiones y -sobre todo desde la década de 1930- fusiones entre las diferentes entidades que integraron o aún integran la Federación.

Otro tema que amerita la atención de los investigadores es el del importante papel que tanto aquella como varias de sus sociedades adjudicaron a la formación cultural de sus miembros. Al respecto, existen los numerosos documentos de la sección cultural de la FAGA (el Ateneo "Curros Enríquez", creado en la década de 1940), de la que se conservan sus libros de actas, correspondencia enviada y recibida, textos de audiciones radiales, etc., y también los libros y cuadernos pertenecientes a las bibliotecas de varias entidades microterritoriales, como la Sociedad Unión Residentes de Entrimo y Lovios, Fomento de Porriño y su Distrito, Unión Hijos de El Grove, etc.

Ligado a lo anterior, el archivo de la Federación constituye una vía de entrada al problema de la identidad lingüística, tema muy poco explorado en el período posterior a $1936^{19}$. Al llegar a Buenos Aires, los gallegos se enfrentaron a la necesidad de adaptarse a las normas de una sociedad distinta y cuyo idioma oficial es el castellano, la misma lengua dominante en Galicia, de donde muchos arribaban monolingües en gallego y cargando el estigma de hablar un idioma que era sinónimo de tonto e ignorante. A ello se añade la presión social del entorno castellanohablante o, cuando menos, la necesidad de comunicarse en un idioma

17 Respecto del liderazgo étnico, véanse los trabajos reunidos en Bernasconi y Frid 2006.

18 Sobre las autorrepresentaciones forjadas por la élite galaica en la Argentina, véase Núñez Seixas 2002.

19 Una aproximación a la situación lingüística de la última oleada migratoria, en Gugenberger 2001. 
franco con los inmigrantes de otras nacionalidades que tampoco solían manejar la lengua oficial del país. De tal modo, en el proceso de incorporación a la sociedad receptora acabaron por entrelazarse la motivación instrumental y la integradora. El fuerte deseo de superación, de ascender socialmente y de brindar a sus hijos un futuro mejor, parece haber sido un factor que también fomentó la falta de transmisión intergeneracional del idioma propio de Galicia. Puede suponerse que el mismo siguió siendo empleado de acuerdo con el código de "lengua de solidaridad" que imperaba en su medio rural originario, que continuó hablándose en el seno de las redes sociales informales y familiares, en las fiestas, y en los momentos de esparcimiento en los centros y sociedades étnicas. Sin embargo, su uso público "formal" debió ser muy reducido. Al menos durante el primer tercio del siglo $\mathrm{XX}$, el idioma gallego se hallaba prácticamente ausente de la documentación interna y de las memorias editadas por las instituciones de emigrantes, y con anterioridad a la década de 1920 rara vez era empleado en los actos públicos de la colectividad. De hecho, su utilización en circunstancias "formales" causaba asombro, y la reacción de la elite no solía ser positiva cuando superaba las funciones secundarias, "permitidas" y más o menos cómico-festivas. La diglosia funcional asociaba y limitaba el uso escrito del gallego a la gastronomía y diversión, junto con la evocación de la comarca de origen. La documentación conservada por la FAGA constituye una herramienta útil para testear que actitud tuvieron ella y las sociedades que reunió en relación a esa lengua en los años posteriores a 1936, otro tema abierto a investigaciones en profundidad.

Por último, la abundante documentación contable disponible permite abordar el estudio de la gestión financiera de las entidades, y de la relación de está con sus variados fines.

\section{A modo de cierre}

Si en las últimas décadas los estudios migratorios han contribuido de manera decisiva a modificar las interpretaciones de la historia de los países sobre los que han reflexionado, ello no sólo se debe a que la inmigración en sí constituye un tema de investigación vasto y apasionante, sino a que supone también una vía de entrada a problemas más generales de la sociedad. Constreñidos por el reducido espacio disponible hemos evitado profundizar en las múltiples implicancias de tal aserto. No obstante, confiamos en que nuestra somera descripción y análisis de la composición y características del archivo de la FAGA, baste para graficar el valor que esos fondos documentales ( $u$ otros similares) poseen para el tratamiento de diversos aspectos de la inmigración y el exilio gallego en la Argentina. Aspectos que, como hemos comentado, exceden largamente su utilidad para la reconstrucción de la vida societaria de la comunidad emigrada o -en el caso de entidades altamente politizadas como la FAGA- la trayectoria de los personajes relevantes de la emigración y el exilio (políticos, intelectuales, artistas), hasta hoy los dos temas más recurrentes entre quienes emplearon dicho acervo.

En cualquier caso, esos estudios requiere como condición de posibilidad la disponibilidad de fuentes idóneas, y éstas de archivos en condiciones de conservarlas, catalogarlas y ponerlas a disposición de los investigadores. De tal modo, la ordenación y preservación del patrimonio deviene en una tarea tan urgente como fundamental. Por desgracia, a la vista del nulo esfuerzo desplegado en tal sentido por buena parte de las sociedades gallegas o genéricamente españolas existentes, parece evidente que un sector no desdeñable de dirigencia étnica se halla en desacuerdo con dicho punto de vista. El destrato con los que a menudo manejan sus fondos documentales (y demás patrimonio material e inmaterial) es, por el contrario, frecuente. Paradigmático resulta, en tal sentido, lo ocurrido con documentación altamente sensible del CRE, desgajada del corpus principal en oscuras circunstancias y trasladada a España (Sierra Bárcena 2005, 2006; Díaz-Regañón Labajo 2005), contrariando el principio básico de mantener la unidad del patrimonio documental, y también las leyes argentinas e internacionales sobre el tráfico de documentos. Otro tanto puede decirse del acervo de la Sociedad Residentes del Municipio de Vedra en Buenos Aires, "prestado" hace ya años a ese concello gallego, y que aún aguarda su devolución a la capital argentina.

Pero no se trata sólo de la desidia de la dirigencia étnica. Últimamente, al calor de la severa crisis que atraviesa el Centro Gallego porteño (institución que atesora una gran pinacoteca, e importantes fondos documentales y bibliográficos), y de la campaña desarrollada 
en Galicia a favor del "regreso" de la obra de Castelao "A derradeira lección do mestre" (conservado en el Centro Galicia de Buenos Aires), despuntó una polémica en relación a quién pertenece el patrimonio cultural gallego en la Argentina. Una amplia mayoría del mismo fue originado en el país austral, como consecuencia indirecta de las migraciones o exilios gallegos a él. Es decir que, con independencia de cuál habría sido la intención de sus autores respecto a que sus obras vieran la luz en Galicia o en otra parte del mundo, las mismas nacieron (o fueron completadas) y existieron hasta el día de hoy en la orilla occidental del Río de la Plata, conforman una parte inescindible del acervo de la comunidad galaico-argentina y, en fin, de la cultura argentina, una de cuyas características centrales es la de ser-precisamente- el resultado de la incesante sumatoria e hibridación de elementos autóctonos y foráneos. Pero si ello no fuese suficiente, la legislación argentina es taxativa en cuanto a la prohibición de la salida del país de las obras de arte, documentos, bibliotecas, etc., existentes en él. Lo que se necesita, entonces, no es que Galicia "recupere" aquello que -con pleno derecho-podemos denominar "patrimonio cultural galaico-argentino", sino crear o potenciar las condiciones para su consolidación y perdurabilidad en la Argentina.

Así las cosas, conviene realzar los trabajos realizados por el MEGA para recuperar y poner en valor la documentación de la FAGA, precisamente porque su trabajo profesional y a largo plazo ha sido a menudo ignorado por la dirigencia de la colectividad. Resguardar el patrimonio constituye una tarea ardua, lenta, monótona y - eventualmente- onerosa. Sin embargo, compensa largamente el esfuerzo invertido en ella, porque si resulta evidente la magnitud del trabajo a desarrollar y sus costos (no sólo materiales), no es menos notorio el beneficio que de ello puede obtenerse, dada su importancia para la Historia y Memoria de Galicia, de sus migraciones y exilio en la Argentina, y de la vida de comunidad galaica en una y otra orilla del océano. Resulta entonces imprescindible que tanto la dirigencia étnica como la colectividad y la comunidad galaico-argentina toda, tomen conciencia de la necesidad imperiosa de abandonar la triste combinación de individualismos, mezquindades, diferencias políticas y/o personales, y de la falta de profesionalismo que desde hace décadas han llevado a verdaderos desastres en cuanto a la pérdida de nuestro patrimonio. Asumir colectivamente la responsabilidad histórica que entraña el hecho del inexorable fin de la primera generación de inmigrantes gallegos, y trabajar de forma coordinada y altruista por el pleno desarrollo de iniciativas amplias y plurales que pongan de relieve el enorme peso demográfico y cultural del colectivo gallego en la sociedad argentina, es la necesidad de la hora. La actitud que los líderes de la colectividad y la comunidad gallega en la Argentina adopten marcará a fuego las posibilidades de éxito de dicha empresa, y con ello la pervivencia de buena parte de los insumos necesarios para la supervivencia y proyección de una identidad galaicoargentina entre las futuras generaciones de la República austral.

\section{Referencias bibliográficas}

Baily, Samuel (1996): "Posibilidades y problemas del cruzamiento de Registros nominativos en el estudio del proceso migratorio italiano", Estudios Migratorios Latinoamericanos 33, pp. 269-285.

Bernasconi, Alicia (1995): "Aproximación al estudio de las redes sociales migratorias a través de las listas de desembarco. Posibilidades y problemas", en M. Bjerg y H. Otero (comps.), Migración y redes sociales en la Argentina moderna. Tandil: CEMLA - IEHS, pp. 191-202.

Bernasconi, Alicia y Carina Frid (eds.) (2006): De Europa a las Américas. Dirigentes y liderazgos (18801960). Buenos Aires: Biblos.

Bjerg, María y Hernán Otero (comps.) (1995): Migración y redes sociales en la Argentina moderna. Tandil: CEMLA - IEHS.

Cagiao Vila, Pilar (1997): Muller e emigración. Santiago de Compostela: Xunta de Galicia.

(1999): “A vida cotiá dos emigrantes galegos en América”, en P. Cagiao Vila (comp.), Galegos en América e americanos en Galicia. Santiago de Compostela: Xunta de Galicia, pp. 115-135.

Cagiao Vila, Pilar y Vicente Peña Saavedra (coms.) (2009): Nós mesmos. Asociacionismo galego na emigración - Asociacionismo gallego en la emigración. Santiago de Compostela: Consello da Cultura Galega.

Cerdeira Louro, Xurxo (2010): Proceso migratorio e sociedades de emigrantes de Vedra: a viaxe cara a modernidade. A Coruña: Deputación Provincial da Coruña. 
Chiloteguy, Miguel (2015): "El Museo de la Emigración Gallega en la Argentina: su misión como reservorio de la memoria histórica y su relación con el público". Ponencia inédita $\left(\mathrm{XI}^{\circ}\right.$ Congreso de la Asociación Internacional de Estudos Galegos). Buenos Aires: Universidad de Buenos Aires.

Da Orden, María Liliana (2005): Inmigración española, familia y movilidad social en la Argentina moderna. Una mirada desde Mar del Plata (1890-1930). Buenos Aires: Biblos.

(2010): Una familia y un océano de por medio. La emigración gallega a la Argentina: una historia a través de la memoria epistolar. Rubí (Barcelona): Antrhopos.

De Cristóforis, Nadia (2009): Proa al Plata: Las migraciones de gallegos y asturianos a Buenos Aires (fines del siglo XVIII y comienzos del XIX). Madrid: Consejo Superior de Investigaciones Científicas.

(2010): Bajo la Cruz del Sur: gallegos y asturianos en el Buenos Aires (1820-1870). A Coruña: Fundación Pedro Barrié de la Maza.

(ed.) (2011). Bajo el signo del franquismo: emigrantes y exiliados gallegos en la Argentina. Santiago de Compostela: Fundación Sotelo Blanco.

De Cristóforis, Nadia y Alejandro Fernández (eds.) (2008): Las migraciones españolas a la Argentina. Variaciones regionales (siglos XIX y XX). Buenos Aires: Biblos.

Devoto, Fernando (2001): "El revés de la trama: políticas migratorias y prácticas administrativas en la Argentina (1919-1949)", Desarrollo Económico 42/162, pp. 281-303.

- (2003): Historia de la inmigración en la Argentina. Buenos Aires: Sudamericana.

Devoto, Fernando y Alejandro Fernández (1990): "Mutualismo étnico, liderazgo y participación política. Algunas hipótesis de trabajo", en D. Armus (comp.), Mundo urbano y cultura popular. Buenos Aires: Sudamericana, pp. 129-152.

Devoto, Fernando y Hernán Otero (2003): "Veinte años después. Una lectura sobre el pluralismo cultural y la historia nacional en la historiografía argentina", Estudios Migratorios Latinoamericanos 50, pp. 181-227.

Díaz, Hernán M. (2007): Historia de la Federación de Sociedades Gallegas. Identidades políticas y prácticas militantes. Buenos Aires: Fundación Sotelo Blanco / Biblos.

Díaz-Regañón Labajo, María Aránzazu (2005): "Fuentes para el estudio del exilio republicano español en Argentina. Los fondos del AGC de Salamanca". Ponencia inédita en el XI ${ }^{\circ}$ Encuentro de Latinoamericanistas españoles. Tordesillas: Consejo Español de Estudios Iberoamericanos / CEEIB e Instituto Interuniversitario de Iberoamérica y Portugal.

Duarte, Ángel (1998): La República del emigrante. La cultura política de los españoles en la Argentina, 1875 1910. Lleida: Milenio.

Farías, Ruy (coord.) (2010). Bos Aires galega. Noia: Toxosoutos.

_ (2011): “Aspectos de la identidad gallega en Buenos Aires (1900-1960)", Madrygal. Revista de Estudios Gallegos 14, pp. 59-69.

Farías Iglesias, Ruy Gonzalo (2010): La inmigración gallega en el sur del Gran Buenos Aires, 1869-1960. Santiago de Compostela: Universidade de Santiago de Compostela.

Fasano, Laura (2014): Los exiliados republicanos en Buenos Aires: labor política y cultural en el ámbito de la comunidad gallega" (1936-1955). Tesis doctoral inédita. Buenos Aires: Universidad de Buenos Aires.

Fernández, Alejandro (2010): “Os inmigrantes galegos e o asociacionismo español de Bos Aires”, en R. Farías (coord.), Bos Aires galega. Noi: Toxosoutos, pp. 163-180.

Fernández, Alejandro y José Carlos Moya (eds.) (1999): La inmigración española en la Argentina. Buenos Aires: Biblos.

Fernández Santiago, Marcelino (2001): “Asociacionismo gallego en Buenos Aires (1936-1960)”, en X. M. Núñez Seixas, La Galicia Austral. La inmigración gallega en la Argentina. Buenos Aires: Biblos, pp. 181-201.

Fernández Vargas, Valentina (1992): “Análisis cuantitativo”, en P. A. Vives, P. Vega y J. Oyamburu (coords.), Historia general de la emigración española a Iberoamérica. Madrid: Historia 16, vol. 1, pp. 579-614.

Fernández Vicente, María José (2005): "En busca de la legitimidad perdida. La política de emigración del régimen franquista, 1946-1965", Estudios Migratorios Latinoamericanos 56, pp. 3-29.

García Sebastiani, Marcela (dir.) (2011): Patriotas entre naciones. Elites emigrantes españolas en Argentina (1870-1940). Madrid: Universidad Complutense de Madrid.

González, Lucas; Jerónimo Boragina, Gustavo Dorado y Ernesto Sommaro (2008). Voluntarios argentinos en la Guerra Civil Española. Buenos Aires: Ediciones del CCC.

Gordon, Milton M. (1964): Assimilation in American Lyfe: The Role of Race, Religion and National Origins. New York: Oxford University Press. 
Gugenberger, Eva (2001): "Identidad, conflicto lingüístico y asimilación: observaciones acerca de la lengua gallega en Buenos Aires", en X. M. Núñez Seixas (ed.), La Galicia Austral. La inmigración gallega en la Argentina. Buenos Aires: Biblos, pp. 251-277.

Lojo, María Rosa (dir.); Marina Guidotti de Sánchez y Ruy Farías (2008): Los "gallegos” en el imaginario argentino. Literatura, sainete, prensa. A Coruña: Fundación Pedro Barrié de la Maza.

Merino Hernando, María Asunción (2012): Emigración, asociacionismo y retorno de los españoles en Argentina (siglos XIX y XX). El diseño y la práctica de su investigación. Madrid: Editora Trotta.

Montenegro, Silvina (2002): La Guerra Civil Española y la política argentina. Tesis de doctorado. Madrid: Universidad Complutense de Madrid (http://eprints.ucm.es/tesis/ghi/ucm-t26475.pdf).

Moya, José C. (2004 [1998]): Primos y extranjeros: La inmigración española en Buenos Aires, 1850-1930. Buenos Aires: Emecé.

Núñez Seixas, Xosé Manoel (1992): O galeguismo en América, 1879-1936. Sada: Edicións do Castro. (1998): Emigrantes, caciques e indianos. O influxo sociopolítico da emigración transoceánica en Galicia (1900-1930). Vigo: Xerais.

(2000): "A parroquia de alén mar: Algunhas notas sobre o asociacionismo local galego en Bos Aires (1904-1936)”, Semata. Ciencias Sociais e Humanidades 11 (Galicia nos contextos históricos, ed. P. Cagiao Vila), pp. 345-379.

(ed.) (2001): La Galicia Austral. La inmigración gallega en la Argentina. Buenos Aires: Biblos.

(2002): O inmigrante imaxinario. Estereotipos, identidades e representacións dos galegos na Arxentina (1880-1940). Santiago de Compostela: Universidade de Santiago de Compostela.

(2006): "Modelos de liderazgo en comunidades emigradas. Algunas reflexiones a partir de los españoles en América (1870-1940)", en A. Bernasconi y C. Frid (eds.), De Europa a las Américas. Dirigentes y liderazgos (1880-1960). Buenos Aires: Biblos, pp. 17-41.

(2007): "Galicia e Arxentina, Galicia na Arxentina", en P. Cagiao Vila y X. M. Núñez Seixas, Os galegos e o Río da Prata. A Coruña: Arrecife Edicións, pp. 11-152.

— (2009): “¿Para qué sirve conservar el patrimonio de la emigración?”, A Grileira 7 (http://www.agrileira.com.ar/agrilev/7C/nota1c.htm).

(2010): “A historiografia das migrações ultramarinas espanholas: Uma visão global”, en Maracanan 6, pp. 11-45.

Núñez Seixas, Xosé Manoel y Raúl Soutelo Vázquez (2005): As cartas do destino. Unha familia galega entre dous mundos, 1919-1971. Vigo: Galaxia.

Ortuño Martínez, Bárbara (2010): El exilio y la emigración española de posguerra en Buenos Aires, 19361956. Tesis doctoral inédita. Alicante: Universidad de Alicante.

Peña Saavedra, Vicente (1991): Éxodo, organización comunitaria e intervención escolar. La impronta socioeducativa de la emigración transoceánica en Galicia. Santiago de Compostela: Xunta de Galicia, 2 vols.

Rodríguez Díaz, Rogelio (2000 [1940]): Historia del Centro Gallego de Buenos Aires. Buenos Aires: Instituto Argentino de Cultura Gallega.

Sanchez Alonso, Blanca (1992): La inmigración española en Argentina. Siglos XIX y XX. Columbres: Archivo de Indianos.

Schwarzstein, Dora (2001): Entre Franco y Perón: Memoria e identidad del exilio republicano español en Argentina. Barcelona: Crítica.

Sierra Bárcena, Carmen (2005): “Archivos de Españoles en América (Argentina y México), Anuario Americanista Europeo 3, pp. 315-325.

(2006): "Noticia sobre la "Guía de Fuentes para la historia de la guerra civil española, exilio, y movimiento obrero". Una base de Datos para acceder a información puntual de fuentes documentales", Olivar 8, pp. 209-214.

Vázquez González, Alexandre (2015): Emigrantes galegos, transportes e remesas (1830-1930). Santiago de Compostela / A Coruña: Consello da Cultura Galega / Fundación Barrié.

Villares, Ramón (2004): Historia de Galicia. Vigo: Galaxia.

Villares, Ramón y Marcelino Fernández (1996): Historia da emigración galega a América. Santiago de Compostela: Xunta de Galicia.

Vives, Pedro A.; Pepa Vega y Jesús Oyamburu (coord. gral.) (1992): Historia general de la emigración española a Iberoamérica. Madrid: Historia 16, 2 vols.

VV.AA. (1996): Fuentes nominativas y migraciones internacionales (Estudios Migratorios Latinoamericanos 33). Buenos Aires: CEMLA. 